\title{
Redefining Second Stage of Labor: Number of Pushing Contractions
}

\author{
Serin M. Bok ${ }^{1} \quad$ Gabriela E. Pena Carmona ${ }^{1} \quad$ Jake Crawford ${ }^{1} \quad$ Ramy Eskander, MD ${ }^{1}$ Mina Desai, PhD $^{1}$ \\ Michael G. Ross, MD, MPH ${ }^{1}$ \\ ${ }^{1}$ Department of Obstetrics and Gynecology, The Lundquist \\ Institute at Harbor-UCLA Medical Center, Torrance, \\ California \\ Am J Perinatol Rep 2020;10:e183-e186. \\ Address for correspondence Michael G. Ross, MD, MPH, Department \\ of Obstetrics and Gynecology, The Lundquist Institute at Harbor-UCLA \\ Medical Center, 1000 W. Carson Street, Torrance, CA 90509-2910 \\ (e-mail: mikeross@ucla.edu).
}

\begin{abstract}
Keywords

- Labor

- pushing

- second stage

- duration
\end{abstract}

The rate of cesarean section increased dramatically from 1996 to 2012 , rising from approximately 21 to $32 \%$ in 20 years, ${ }^{1}$ with the primary cesarean section rate increasing from 14 to nearly $22 \%$. Though there has been a small decrease in the national cesarean section rate of $31.9 \%$ in 2016, total cesarean section rates in 2016 ranged from 22.3 to over $38 \%$ depending upon the state, ${ }^{1}$ indicating significant variance in practice patterns. Among all primary cesarean sections, labor arrest accounts for approximately one-third of cases. The American College of Obstetricians and Gynecologists and The Society for

received

July 4, 2019

accepted

November 10, 2019
DOI https://doi.org/

10.1055/s-0040-1709982. ISSN 2157-6998.
Maternal-Fetal Medicine Obstetric Care Consensus ${ }^{2}$ recommended that a specific absolute maximum length of time spent in the second stage of labor beyond which all women should undergo operative delivery has not been identified. Recommendations also suggested that before diagnosing arrest of labor in the second stage, one should provide at least 2 hours of pushing in multipara women and at least 3 hours of pushing in primipara women, and longer durations may be appropriate with the use of epidural analgesia or fetal malposition.
Copyright $\odot 2020$ by Thieme Medical Publishers, Inc., 333 Seventh Avenue, New York, NY 10001, USA. Tel: +1(212) 760-0888.
License terms

(요 (1) $\Theta \circledast$ 
Significant controversy remains regarding the length of the second stage. Depending upon the study, investigators have concluded that maternal and neonatal morbidities significantly increase with second stage beyond 3 hours, ${ }^{3}$ beyond 2 hours in primipara patients, ${ }^{4}$ beyond 3 hours in primipara and 2 hours in multipara ${ }^{5}$ women or beyond 3 hours in multipara ${ }^{6}$ patients. In contrast, several reports have suggested that the second stage of labor does not need to be terminated for duration alone ${ }^{7}$ and that there is no evidence that prolonged second stage of labor has a significant impact on fetal morbidity. ${ }^{8}$ A large retrospective cohort study (2002-2008) demonstrated small increases in fetal and maternal morbidity among patients delivering vaginally after prolonged second stage of labor. ${ }^{9}$ A more recent secondary analysis of an observational cohort study (2008-2011) also demonstrated that a longer duration of pushing was associated with a small increase in neonatal morbidity, though $78 \%$ of nulliparous women delivered vaginally even after 4 hours of pushing. ${ }^{10}$ In a prospective randomized study, the extension of second stage labor for one additional hour in singleton, nulliparous women with epidural anesthesia, significantly decreased the incidence of cesarean section. ${ }^{11}$

Numerous studies have examined effects of maternal parameters on the second stage of labor, including maternal hypertension, ${ }^{12}$ body mass index, ${ }^{13,14}$ age, ${ }^{15,16}$ maternal position, ${ }^{17,18}$ fetal head malpresentation, ${ }^{19,20}$ and whether Valsalva or open pushing techniques. ${ }^{21}$ Although delayed pushing has been advocated for patients, particularly those with epidural analgesia, there appears to be an increase in several adverse outcomes (chorioamnionitis, postpartum hemorrhage) with this procedure. ${ }^{22,23}$ Consequently, controversy remains as to how to best manage the second stage of labor to optimize the rate of successful vaginal delivery and minimize maternal and infant morbidity.

In nearly all studies, the second stage is quantified by time. Yet the frequency of uterine contractions may vary by at least twofold, from one contraction every 2 minutes to one every 4 minutes or more. Pushing may be limited to every other contraction to prevent fetal acidosis in the presence of heart rate decelerations and pushing effort may vary with the use of epidural. As the primary factor for descent and ultimate vaginal delivery is maternal pushing, the number of pushing contractions may represent a better quantification of the second stage for predicting the likelihood of successful vaginal delivery or fetal/maternal morbidity. To examine the potential for quantifying the number of pushing contractions, we performed a feasibility study to assess the number of pushing contractions needed for a spontaneous vaginal delivery (SVD) among primipara and multipara patients.

\section{Methods}

The study was designed to determine the number of pushing contractions among primipara versus multipara patients who underwent successful vaginal delivery. This study was approved by the Institutional Review Board at Los Angeles Biomedical Research Institute at Harbor-UCLA Medical Center. Deliveries at Harbor-UCLA Medical Center were analyzed sequentially beginning January 1, 2017. Patients were selected for having a successful SVD of a singleton, term ( $\geq 37$ weeks) newborn, and included both spontaneous and induced labor. Data for the first 100 primipara and 100 multipara SVD were analyzed. PowerChart (Cerner, North Kansas City, MO) maternal records were accessed for maternal demographic data, obstetrical details, and newborn outcome. Ethnicity was not recorded, though the labor population at Harbor-UCLA Medical Center approximates 80\% Hispanic ethnicity. Subsequently, FetaLink (Cerner) monitor tracings were examined to quantify the number of maternal pushing contractions, by recognition of uterine tocodynamometer or intrauterine pressure catheter (IUPC) waveforms, in combination with physician and nursing chart notes regarding pushing activity. Two investigators (S.M.B., G.E.P.C.) were trained to discriminate pushing from nonpushing contractions and subsequently quantified each of the second stage labors. Random patient recordings were counted and confirmed by the senior investigator (M.G.R.) for quality control.

The beginning of the second stage was defined as the point at which patients were observed to be completely dilated. "Delayed pushing" time was included in the duration (minutes) of second stage, for the purpose of this study. Pushing efforts were quantified as pushing contractions, though the patients typically were instructed for three (approximately 10 second) pushing efforts during each second stage contraction. Only patients with external or IUPC tracings were utilized in which nonpushing and pushing contraction efforts were readily discernable.

Although there was no prior data available for sample size calculation, we assumed a mean of 20 versus 15 pushing contractions for primipara and multipara patients, with a standard deviation of $10, \alpha$ error of 0.5 , and power of $80 \%$. This resulted in a sample size requirement of 63 patients in each group to compare primipara and multipara pushing efforts. Due to the lack of prior data for sample size calculation, a sample size of 100 patients in each group was selected.

Primipara and multipara patients were compared for second stage duration and number of pushing contractions. Statistical analysis was performed for using unpaired $t$ test, Chi-square, and analysis of variance, as appropriate. Data are presented as mean \pm SD for demographic data and mean \pm standard error of mean (SEM) for quantification of pushing contractions.

\section{Results}

A total of 108 primipara and 137 multipara women with SVDs were screened to obtain 100 patients with qualifying uterine activity tracings in each group. Monitor tracings were inadequate for assessment of uterine activity in 8 primipara and 37 multipara patients.

Primipara patients were significantly younger than multipara patients $(25.02 \pm 0.62$ vs. $29.11 \pm 0.64$ years; $p<0.01)$ though weights were equivalent among the groups $(81.9 \pm 21.3$ vs. $80.2 \pm 16.3 \mathrm{~kg})$. Among the multipara patients, parity averaged $1.99 \pm 1.07$. Gestational age was longer in primipara as compared with multipara patients $(272.4 \pm 5.8$ vs. $269.9 \pm 5.1 \mathrm{~d} ; p<0.01)$, though there was no 
difference in the use of labor induction ( 45 vs. $32 \%$ ). Primiparas were more likely to receive labor epidurals than multiparas (83 vs. $67 \% ; p<0.01$ ). The proportion of patients receiving oxytocin in the first stage of labor was greater in primiparas (69 vs. $51 \% ; p<0.01$ ), though there was no difference in the use of oxytocin in the second stage (38 vs. 26\%). Primiparas more frequently utilized IUPC monitoring during labor (38 vs. $18 \% ; p<0.01$ ).

Newborn APGAR scores were similar among primipara and multipara patients at $1(8.3 \pm 1.4$ vs. $8.4 \pm 1.3)$ and 5 minutes ( $8.9 \pm 0.6$ vs. $8.8 \pm 1.2$ ). Gender distribution was $55 \%$ male in primiparas and $51 \%$ male in multiparas. Delayed pushing was used commonly for brief periods of time, as $91 \%$ of primiparas had delayed pushing for $29.4 \pm 63.0$ minutes and $59 \%$ of multiparas had delayed pushing for $9.6 \pm 21.9$ minutes.

Pushing contractions were easily recognized by a typical pattern of three peaks during a contraction and were consistent with physician and nursing chart comments. Primipara women required significantly more pushing contractions than did multiparas (mean \pm SEM) $(17.3 \pm 1.7$ vs. $5.5 \pm 0.7$ pushing contractions; $p<0.001$ ) in accord with a longer second stage $(86.7 \pm 7.8$ vs. $27.2 \pm 4.9 \mathrm{~min} ; p<0.001)$. The 95 percentile for pushing contractions was markedly greater among primiparas than multiparas (53.7 vs. 14.9 pushes; $p<0.05$ ). Among the multipara patients, compared with para 2, para 3 patients required a reduced number of pushing contractions (7.5 vs. 4.1 pushes), though there was no further decrease with increasing parity. The use of epidural was associated with greater pushing contractions among both primiparas $(18.5 \pm 1.8$ vs. $10.8 \pm 0.8 ; p<0.01)$ and multiparas $(6.1 \pm 0.8$ vs. $4.1 \pm 0.3 ; p<0.01)$. Increasing newborn weight $(<3,000$, $3,000-3,500,>3,500 \mathrm{~g}$ ) demonstrated a trend for increased pushing contractions among primiparas (16.9, 16.5, 19.8 pushes; $p<0.01$ respectively) though not multiparas (3.8, 6.5, 5.0 pushes), respectively. Female infants required fewer pushing contractions than did male infants among both primipara ( $16.6 \pm 2.6$ vs. $17.8 \pm 2.3 ; p<0.001)$ and multipara patients ( $4.8 \pm 0.5$ vs. $6.1 \pm 1.3 ; p<0.001)$.

\section{Discussion}

The results of the present study demonstrate the feasibility of quantifying the number of pushing contractions rather than solely time duration of the second stage. Primipara women required significantly more pushing contractions than multiparas in accord with a longer duration second stage, and the 95th percentile for pushing contractions was markedly greater for primiparas than that for multiparas. Compared with a para 2, para 3 patients required a reduced number of pushing contractions though there was no further decrease with increasing parity. In both primipara and multipara patients, use of epidural was associated with a greater number of pushing contractions, and newborn weight showed a trend for increased pushing contractions among primipara, though not multipara patients.

The time duration of second stage that we observed is similar to that noted in prior studies of primarily Hispanic or mixed ethnicity patient populations. ${ }^{24-26}$ As reported by Jones and Larson, ${ }^{24}$ the mean duration of the second stage of labor among Hispanic nulliparous and multiparous women was 54.2 and 22.2 minutes, respectively. Of note, much of the literature has focused upon the 95th percentile duration of the second stage. However, in counseling women preparing for labor, a mean or median value may be more useful. Furthermore, knowledge of the number of pushing contractions required, adjusted for individual findings (e.g., epidural, fetal position) potentially may have a motivational value.

We did not specifically explore the effects of delayed pushing. Although reports indicate that delayed pushing results in a decrease in the time pushing, ${ }^{22,23}$ it remains to be determined if it reduces the number of pushing contractions required. We did not assess the adequacy or strength (i.e., Montevideo units) of uterine contractions in the second stage as intrauterine pressure transducer measurements are elevated in response to maternal pushing efforts. As previously demonstrated, the use of epidural was associated with a longer duration of the second stage and an increased number of pushing contractions. This likely represents the reduced maternal exertion and intrabdominal pressure associated with epidural analgesia.

As the aim of the study was to confirm the feasibility of quantifying second stage labor by number of pushing contractions, we included only patients who had successful SVD. Furthermore, we did not examine rates of neonatal or maternal morbidity associated with these deliveries. These results do not include potential patients with prolonged second stages requiring cesarean section or operative vaginal delivery. Future studies which define thresholds for the number of pushing contractions associated with SVD versus operative vaginal delivery or second stage cesarean section may provide valuable predictive information. Further studies also may quantify the number of pushing contractions associated with maternal (e.g., age, type of pushing, position) and fetal characteristics (e.g., head position) and assess the association of number of pushing contractions with maternal and neonatal morbidity.

In summary, the present findings demonstrate the feasibility of quantifying the length of second stage as the number of maternal pushing contractions. In view of the variation in the frequency of uterine contractions and the use of delayed pushing, the number of pushing contractions may ultimately be a useful measure for physicians and nurses and a motivational guide for patients as to what is necessary to achieve a vaginal delivery.

\section{Conflict of Interest}

None.

\section{References}

1 Martin JA, Hamilton BE, Osterman MJK, Driscoll AK, Drake P. Births: final data for 2016. Natl Vital Stat Rep 2018;67(01):1-55

2 Caughey AB, Cahill AG, Guise JM, Rouse DJ; American College of Obstetricians and Gynecologists (College); Society for MaternalFetal Medicine. Safe prevention of the primary cesarean delivery. Am J Obstet Gynecol 2014;210(03):179-193 
3 Bleich AT, Alexander JM, McIntire DD, Leveno KJ. An analysis of second-stage labor beyond 3 hours in nulliparous women. Am J Perinatol 2012;29(09):717-722

4 Le Ray C, Audibert F, Goffinet F, Fraser W. When to stop pushing: effects of duration of second-stage expulsion efforts on maternal and neonatal outcomes in nulliparous women with epidural analgesia. Am J Obstet Gynecol 2009;201(04):361.e1-361.e7

5 Allen VM, Baskett TF, O'Connell CM, McKeen D, Allen AC. Maternal and perinatal outcomes with increasing duration of the second stage of labor. Obstet Gynecol 2009;113(06):1248-1258

6 Cheng YW, Hopkins LM, Laros RK Jr, Caughey AB. Duration of the second stage of labor in multiparous women: maternal and neonatal outcomes. Am J Obstet Gynecol 2007;196(06):585. e1-585.e6

7 Rouse DJ, Weiner SJ, Bloom SL, et al; Eunice Kennedy Shriver National Institute of Child Health and Human Development Maternal-Fetal Medicine Units Network. Second-stage labor duration in nulliparous women: relationship to maternal and perinatal outcomes. Am J Obstet Gynecol 2009;201(04):357.e1-357.e7

8 Janni W, Schiessl B, Peschers $U$, et al. The prognostic impact of a prolonged second stage of labor on maternal and fetal outcome. Acta Obstet Gynecol Scand 2002;81(03):214-221

9 Laughon SK, Berghella V, Reddy UM, Sundaram R, Lu Z, Hoffman MK. Neonatal and maternal outcomes with prolonged second stage of labor. Obstet Gynecol 2014;124(01):57-67

10 Grobman WA, Bailit J, Lai Y, et al; Eunice Kennedy Shriver National Institute of Child Health and Human Development (NICHD) Maternal-Fetal Medicine Units (MFMU) Network. Association of the duration of active pushing with obstetric outcomes. Obstet Gynecol 2016;127(04):667-673

11 Gimovsky AC, Berghella V. Randomized controlled trial of prolonged second stage: extending the time limit vs usual guidelines. Am J Obstet Gynecol 2016;214(03):361.e1-361.e6

12 Bregand-White JM, Kominiarek M, Hibbard JUCOSL. OS030. Hypertension and labor duration: does it take longer? Pregnancy Hypertens 2012;2(03):192

13 Robinson BK, Mapp DC, Bloom SL, et al; Eunice Kennedy Shriver National Institute of Child Health and Human Development (NICHD) of the Maternal-Fetal Medicine Units Network (MFMU). Increasing maternal body mass index and characteristics of the second stage of labor. Obstet Gynecol 2011;118(06):1309-1313
14 Carlhäll S, Källén K, Blomberg M. Maternal body mass index and duration of labor. Eur J Obstet Gynecol Reprod Biol 2013;171(01): 49-53

15 Papadias K, Christopoulos P, Deligeoroglou E, et al. Maternal age and the duration of the second stage of labor. Ann N Y Acad Sci 2006;1092:414-417

16 O'Connell MP, Hussain J, Maclennan FA, Lindow SW. Factors associated with a prolonged second state of labour-a casecontrolled study of 364 nulliparous labours. J Obstet Gynaecol 2003;23(03):255-257

17 Moraloglu O, Kansu-Celik H, Tasci Y, et al. The influence of different maternal pushing positions on birth outcomes at the second stage of labor in nulliparous women. J Matern Fetal Neonatal Med 2017;30(02):245-249

18 Ragnar I, Altman D, Tydén T, Olsson SE. Comparison of the maternal experience and duration of labour in two upright delivery positions-a randomised controlled trial. BJOG 2006; 113(02):165-170

19 Senécal J, Xiong X, Fraser WD; Pushing Early Or Pushing Late with Epidural study group. Effect of fetal position on second-stage duration and labor outcome. Obstet Gynecol 2005;105(04):763-772

20 Ghi T, Maroni E, Youssef A, et al. Sonographic pattern of fetal head descent: relationship with duration of active second stage of labor and occiput position at delivery. Ultrasound Obstet Gynecol 2014; 44(01):82-89

21 Yildirim G, Beji NK. Effects of pushing techniques in birth on mother and fetus: a randomized study. Birth 2008;35(01):25-30

22 Tuuli MG, Frey HA, Odibo AO, Macones GA, Cahill AG. Immediate compared with delayed pushing in the second stage of labor: a systematic review and meta-analysis. Obstet Gynecol 2012;120 (03):660-668

23 Cahill AG, Srinivas SK, Tita ATN, et al. Effect of immediate vs delayed pushing on rates of spontaneous vaginal delivery among nulliparous women receiving neuraxial analgesia: a randomized clinical trial. JAMA 2018;320(14):1444-1454

24 Jones M, Larson E. Length of normal labor in women of Hispanic origin. J Midwifery Womens Health 2003;48(01):2-9

25 Albers LL. The duration of labor in healthy women. J Perinatol 1999;19(02):114-119

26 Albers LL, Schiff M, Gorwoda JG. The length of active labor in normal pregnancies. Obstet Gynecol 1996;87(03):355-359 